\title{
Conversion from spatial patterns of activity to sequences of neuronal activations using gate interneurons
}

\author{
Eduardo Conde-Sousa ${ }^{1,2}$, Paulo Aguiar ${ }^{1,2^{*}}$ \\ From Twenty Second Annual Computational Neuroscience Meeting: CNS*2013 \\ Paris, France. 13-18 July 2013
}

Activities such as playing the piano or moving a hand to a particular object and grab it require the execution of a finite sequence of actions. Long-term learning processes make the replication of these activities natural and reliable. The work presented here focus on the problem of using spatial neuronal activity patterns (specific constellations of neurons which become active within a short time window) to specify different sequences of activations on a population encoding learned elementary actions. Consider, for example, the case where each neuron or synchronized group of neurons in the premotor cortex triggers an elementary movement (e.g. basic movements of an arm). Different basic movements should be arranged in sequences depending if the goal is to grab an object from a table, or catch it in flight. Distinct complex actions are therefore specified by different sequences of neuronal activations in the same population [1,2], and each sequence must be recovered as a whole unit.

Recently we proposed a novel class of excitatory interneurons, named "gate interneurons", which can play a key role in storing and recalling short-term memory sequences [3]. In the gate interneurons framework, a major pathway between principal neurons is mediated not by synapses but by the gate interneurons giving them the ability to control the flow of activations (routing) in the principal neurons population. Here we build upon this work and show that gate interneurons can be used to guide a learning process allowing the conversion of specific spatial activity patterns into specific sequences of activations. This conversion is possible because the principal neuron population establishes connections to gate interneurons which then feedback the principal neuron

${ }^{1}$ Faculty of Sciences, University of Porto, Porto, Portugal

Full list of author information is available at the end of the article

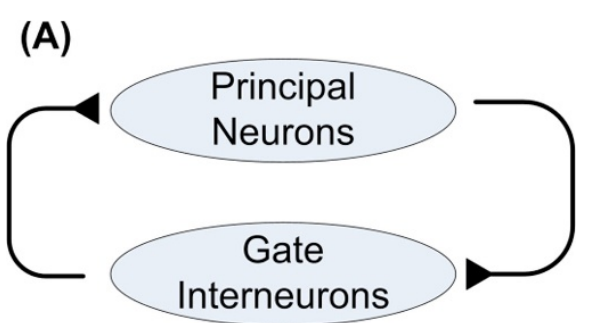

(B) Gate interneurons

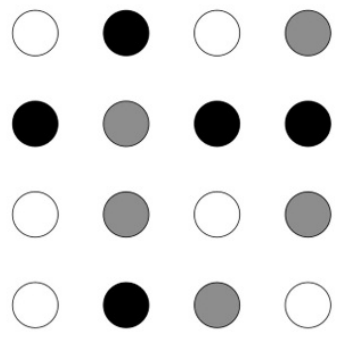

(C) Principal neurons

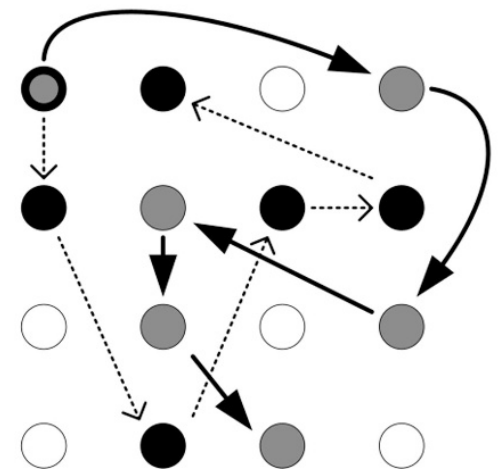

Figure 1 (A) Circuit diagram. (B), (C) Different ensembles in the gate interneuron population (gray or black spatial activations) cause different sequences of activations in principal neuron population. 
population (Figure 1A). Depending on which ensemble of gate interneurons is active, the feedback excitation impinges in different principal neurons, resulting in a different sequence of activations.

In the proposed model, an action that needs the activation of principal neuron A followed by the activation of principal neurons $B$, requires the activity of a gate interneuron responsible coding the sequential pattern $\mathrm{AB}$. If gate interneuron $A B$ is not active, then the sequence will not proceed to $B$ and will flow to another principal neuron, depending which other gate interneurons are available. Consider, as in Figure $1 \mathrm{C}$, a network of 16 principal neurons (or groups of synchronous neurons represented by one unit in the model). To execute some complex action it may be needed to follow the sequence $1 \rightarrow 4 \rightarrow 12 \rightarrow 6 \rightarrow 10 \rightarrow 15$ while in another complex action it may be required to follow the sequence $1 \rightarrow 5 \rightarrow 14 \rightarrow 7 \rightarrow 8 \rightarrow 2$, both starting in neuron 1 . Depending on which gate interneurons are previously activated (spatial patterns labeled in gray and black in Figure 1B,C), the sequence may follow the first path (labeled in gray), or the second (labeled in black).

\section{Author details}

${ }^{1}$ Faculty of Sciences, University of Porto, Porto, Portugal. ${ }^{2}$ Center for Mathematics of University of Porto, Porto, Portugal.

Published: 8 July 2013

\section{References}

1. Pastor-Bernier A, Tremblay E, Cisek P: Dorsal premotor cortex is involved in switching motor plans. Frontiers in Neuroengineering 2012, 5 .

2. Salinas E: Rank-order-selective neurons form a temporal basis set for the generation of motor sequences. The Journal of Neuroscience 2009, 29(14):4369-4380.

3. Conde-Sousa E, Aguiar P: A working memory model for serial order which stores information in the intrinsic excitability properties of neurons. JCompNeurosci 2013, doi: 10.1007/s10827-013-0447-7.

\section{doi:10.1186/1471-2202-14-S1-P3}

Cite this article as: Conde-Sousa and Aguiar: Conversion from spatial patterns of activity to sequences of neuronal activations using gate interneurons. BMC Neuroscience 2013 14(Suppl 1):P3.

\section{Submit your next manuscript to BioMed Central} and take full advantage of:

- Convenient online submission

- Thorough peer review

- No space constraints or color figure charges

- Immediate publication on acceptance

- Inclusion in PubMed, CAS, Scopus and Google Scholar

- Research which is freely available for redistribution

Submit your manuscript at www.biomedcentral.com/submit
C Biomed Central 